\title{
The effectiveness of enzyme preparations in broiler chicken diets
}

\author{
Liudmila Reznichenko, Aleksei Reznichenko, Roman Shcherbinin, Andrej Manokhin
}

Belgorod State Agricultural University named after V.Y. Gorin, 1, Vavilova St., Mayskiy settlement, 308503, Belgorod district, Belgorod region, Russia

\begin{abstract}
With the wrong use of antibiotics for agricultural poultry, the effectiveness of their effect on the body is noticeably reduced, since pathogenic and conditionally pathogenic microorganisms become resistant to them for a certain time, i.e., there is a process of "addiction". Experience shows that enrichment of feed rations with enzyme preparations and vitamins improves the functioning of the stomach and intestines, increases the natural resistance of the body, as a result of which the mortality of poultry decreases, the absorption of feed is significantly increased and their costs per unit of production are reduced. We studied the effect of the new vitamin-enzyme complex Vitaferm on the organism of broilers against the background of the exclusion of antibacterial drugs from the antiepizootic measures scheme and compared its effect with the enzyme preparation Avizim 110. The studies carried out indicate the positive effect of Vitafarm and Avizim 110 on the poultry organism, which is manifested by an increase in average daily poultry gains, an increase in safety, and a decrease in feed costs per unit of production. These changes can be explained by the normalization of the gastrointestinal tract of broiler chickens and increased immunity. Antibiotics suppress the body's immune system; upset the balance of the intestinal microflora. For the complete or partial exclusion of antibacterial drugs from the scheme of antiepizootic measures, it is proposed to apply to broiler chickens with feed the vitamin-enzyme complex of Vitaferm at the rate of $15.0 \mathrm{~g} / \mathrm{kg}$ starting from day old for 10 days.
\end{abstract}

\section{Introduction}

As a result of the uncontrolled use of antibacterial drugs, the effectiveness of their impact on poultry is reduced. Negative processes develop in the bird's body: the number of useful intestinal microflora decreases. At the same time, strains with altered ecological characteristics accumulate in the composition of populations of useful microflora. In representatives of gram-positive microflora, antagonistic, adhesive, and biochemical activity decreases, and in gram-negative bacteria, virulent properties increase. Violations of the physiological, immunological mechanisms of protection of the animal organism create conditions for the development of infectious processes caused by its pathogenic microflora and saprophytic bacteria from the environment. Genetic determinants of antibiotic resistance, getting into the genomes of pathogenic bacteria species, make the infectious diseases caused by them practically incurable by existing drugs [1].

It is believed that the use of various antibiotics and other antibacterial drugs in chickens during the first day of life often leads to inhibition of the development of cilia of the intestinal epithelium, disruption of the formation of useful microflora in the digestive organs, dysbacteriosis, and necrotic enteritis, which reduces the growth of poultry and causes increased mortality [2, 3].

Exogenous enzymes are an important component of poultry diets; they improve the digestibility of feed, reduce environmental pollution and reduce the cost of production, which in turn leads to an increase in the safety and productivity of poultry [4]. Enzymes (enzymes) are specific proteins that play the role of biological catalysts in a living organism. They, in contrast to hormones and biostimulants, do not act on the poultry organism, but on the feed components in the gastrointestinal tract, they do not accumulate in the body and livestock products [5]. Enzymes are mostly very specific; they act selectively on certain substances (substrates) or groups of substances.

Enzyme preparations are biologically active nutritional factors that have a positive effect on digestion processes. They are products of the vital activity of microorganisms - bacteria, microscopic fungi, actinomycetes, etc. [6].

There are two main strategies for the use of exogenous enzymes in industrial animal husbandry. The first is to change the composition of the diet to reduce feed costs and maintain the growth and productivity of animals at the same level. This can be achieved by replacing wheat, barley, or corn with cheaper by-

Corresponding author: reznichenko6531@gmail.com 
products. The second option involves the addition of enzymes to the standard feed, which leads to the more intensive growth of animals and, consequently, to an increase in the amount of production. To be effective when added to feed, these enzymes must be stable during storage and compatible with other ingredients [7].

When using enzyme preparations containing mainly cellulases, pectinases, and hemicellulases, the enzymatic lysis of starch and proteins is enhanced. This is preceded by the cleavage of intermolecular bonds in supramolecular fiber complexes, that is, between cellulose, hemicellulose, and pectin, as well as intramolecular bonds in these substances. This increases the availability of starch, protein, and lipids for endogenous and exogenous hydrolases, and their digestibility. This sequence of changes in the processes of digestion and metabolism of nutrients under the influence of enzyme preparations was established in vitro experiments - during incubation of feed with enzymes in different sequences, as well as on-farm animals [8].

There are several anti-nutritional factors: the nonstarchy polysaccharides of some cereals increase the viscosity of the intestinal contents, which negatively affects the digestion process; phytates that provoke mineral deficiency; undigested starch and protein. Although poultry has sufficient amylase and protease to eliminate the latter, the use of exogenous enzymes can help optimize the degradation processes [9].

Cereals (rye, wheat, barley, oats) are the main components of the diet of poultry. They are leading in the content of non-starchy polysaccharides - cellulose, pectin substances, part of beta-glucans and pentosans and are difficult to digest, their excess in food in monogastric animals prevents the access of digestive enzymes to nutrients, which consequently worsens their use [10].

In the digestive tract of the bird, its enzymes are produced, with the help of which the nutrients of the feed are digested. However, animals, especially monogastric ones, practically do not have their enzymes that digest non-starchy polysaccharides, which is why they are practically not absorbed by the body. Moreover, non-starchy polysaccharides prevent animals and birds from accessing and digesting other nutrients by their enzymes. In the digestive tract of birds, non-starchy polysaccharides form a viscous solution that envelops granules of starch and proteins. There are two negative consequences: liquid and sticky droppings, in which infection spreads, and a decrease in poultry productivity.

Currently, many manufacturers offer ready-made feeds with enzyme additives, most of which contain enzymes that destroy non-starch polysaccharides of the cell wall of grain - cellulase, hemicellulase, amylase [11].

The use of enzymes facilitates the selection of the feed base, which makes it possible to work with any type of ration. The use of enzymes allows the use of cheaper ingredients in animal feeding and at the same time obtaining good results [12].

It should be noted that modern poultry farming is focused on reducing antibacterial drugs, in connection with which it is especially important to use natural poultry growth stimulants to obtain environmentally friendly products. Such stimulants are vitamins, enzymes, probiotics, prebiotics, phytobiotics [13-15].

Our developments are aimed at replacing antibacterial drugs in the diets of farm animals with other substances that are harmless to the human body.

The purpose of the experiment is to study the effect of the new vitamin-enzyme complex Vitafarm on the organism of broiler chickens to exclude or reduce the use of antibacterial drugs in poultry farming and compare its effect with Avizim 110.

\section{Material and method of analysis}

Experimental studies were carried out on broiler chickens in a poultry laboratory. Educational and Scientific Innovation Center Agrotekhnopark FSBEI HE Belgorod State Agrarian University named after V. Y. Gorin. The formation of the control and experimental groups of poultry was carried out according to the principle of analogs.

Vitaferm is a loose powdery mass of light gray color with a specific odor. Its composition: pepsin - $1.5 \mathrm{mg}$, pancrease - $1.5 \mathrm{IU}$; vitamins, per $1 \mathrm{~g}$ : A - $500 \mathrm{IU}$; E $0.74 \mathrm{mg}$; B1 - $0.17 \mathrm{mg}$; B2 - $0.17 \mathrm{mg}$; D3- 44ME; B6 $0.18 \mathrm{mg}$; PP - 2mg; folic acid - $0.06 \mathrm{mg}$; pantothenic acid - $0.75 \mathrm{mg}$; biotin - $0.002 \mathrm{mg}$; B12 - $0.36 \mathrm{mcg}$; C - 9.2 $\mathrm{mg}$; Citric acid - $20 \mathrm{mg}$; the rest is sucrose.

Avizim 110 is a microbial polyenzyme preparation containing $\beta$-glucanase, xylanase, and protease in the amount of $100 \mathrm{U} / \mathrm{g}, 300 \mathrm{U} / \mathrm{g}, 800 \mathrm{U} / \mathrm{g}$, respectively, is a fine-grained powder of light brown color, with a weak specific odor, insoluble in water.

The nature of the effect of Vitaferm and Avizim on the body of chickens was judged by clinical indicators, changes in protein, carbohydrate, and mineral metabolism, growth rate, and productivity.

Biochemical parameters were determined by conventional methods. The Hitachi hematology analyzer was used.

The digital material obtained in all experiments was subjected to statistical processing on a personal computer according to the generally accepted methods of variation statistics with the calculation of the Student's argument (td). The difference between the compared values was considered significant at $\mathrm{p} £ 0,05$ [9].

\section{Test results and discussion}

To research the principle of analogs, 4 groups of broiler chickens of day-old age were formed, 50 heads each. The first group was the control; the second, third and fourth are experienced. The second experimental group received Vitaferm in addition to the diet for 10 days at the rate of $10.0 \mathrm{~g} / \mathrm{kg}$ of feed; the third experimental group was fed Avizim 110 at a dose of $1.0 \mathrm{~g} / \mathrm{kg}$ for the same period. For the fourth experimental group, the vitamin-enzyme complex was also used for 10 days with food at the rate of $10.0 \mathrm{~g} / \mathrm{kg}$, but antibiotics were completely excluded from the antiepizootic measures 
scheme.

Chickens from the control, second and third experimental groups received a diet according to the scheme adopted in the farm with the use of all antibacterial drugs (starting from 2 days of age, cypromag was added to the water at the rate of $5 \mathrm{ml}$ per $10 \mathrm{~L}$ for 5 days and this drug was used from 20 days of age. age with water for 5 days).

Observation of the bird was carried out during the entire growing period. The experiment scheme is presented in Table 1.

As a result of the conducted studies, it was found that at the end of the experimental period, the average daily gains of chickens in the second and third experimental groups exceeded the control values by 5.0 and $4.8 \%$, respectively, while in the fourth experimental group, where antibiotics were not used, the average daily gains in poultry were higher than the control by $5.3 \%$.

Table 1. Scheme of research on broiler chickens

\begin{tabular}{|l|l|l|c|}
\hline Groups & $\begin{array}{l}\text { Number of } \\
\text { heads }\end{array}$ & Drugs used & Doze \\
\hline 1 - control & 50 & Basic Diet (BD) & - \\
\hline 2 - experienced & 50 & BD + Vitaferm & $10,0 \mathrm{~g} / \mathrm{kg}$ \\
\hline 3 - experienced & 50 & BD + Avizim 110 & $1,0 \mathrm{~g} / \mathrm{kg}$ \\
\hline 4 - experienced & 50 & BD (no antibacterial drugs) + Vitaferm & $10,0 \mathrm{~g} / \mathrm{kg}$ \\
\hline
\end{tabular}

Table 2. Results of testing Vitafarm on broiler chickens

\begin{tabular}{|l|c|c|c|c|}
\hline \multirow{2}{*}{ Indicators } & \multicolumn{4}{|c|}{ Groups } \\
\cline { 2 - 5 } & 1-control & 2-experienced & 3-experienced & 4-experienced \\
\hline $\begin{array}{l}\text { Number of heads at the beginning } \\
\text { of the experiment }\end{array}$ & 50 & 50 & 50 & 50 \\
\hline at the end of the experiment & 48 & 49 & 49 & 50 \\
\hline Safety,\% & 96 & 98 & 98 & 100 \\
\hline Average daily gain, g & 63,8 & 67,0 & 66,9 & 67,2 \\
\hline Feed costs per 1 kg gain, $\mathrm{kg}$ & 1,69 & 1,68 & 1,68 & 1,67 \\
\hline
\end{tabular}

During the entire experimental period, the death of chickens was noted in the control, second, and third experimental groups. Feed costs in all experimental groups were below the control values.

The studies carried out indicate the positive effect of Vitaferm and Avizim 110 on the poultry organism, which can be explained by the normalization of the digestive system of broiler chickens after the use of the drugs. It should be noted that the abolition of antibiotics against the background of the use of a vitamin-enzyme complex contributed to an increase in the growth of poultry. As you know, antibiotics suppress the body's immune system; upset the balance of the intestinal microflora.

The biochemical composition of blood is presented in Table 3.

Table 3. Biochemical parameters of the blood of broiler chickens, $n=20(M \pm m)$

\begin{tabular}{|l|c|c|c|c|}
\hline \multirow{2}{*}{ Indicators } & \multicolumn{4}{|c|}{ Groups } \\
\cline { 2 - 5 } & 1 -control & 3 -experienced & 4-experienced & 5 -experienced \\
\hline Total protein, g / 1 & $56,7 \pm 1,29$ & $59,5 \pm 1,32$ & $59,8 \pm 1,23$ & $59,4 \pm 1,37$ \\
\hline Album in,\% & $41,9 \pm 0,48$ & $44,5 \pm 0,49 * *$ & $44,9 \pm 0,46^{* *}$ & $44,8 \pm 0,50^{* *}$ \\
\hline$\alpha$ - globulins, \% & $17,7 \pm 1,32$ & $15,8 \pm 1,34$ & $15,9 \pm 1,62$ & $15,4 \pm 1,66$ \\
\hline$\beta$-globulins,\% & $15,6 \pm 0,28$ & $17,2 \pm 0,30^{*}$ & $17,1 \pm 0,24^{*}$ & $16,9 \pm 0,25^{*}$ \\
\hline$\gamma$-globulins,\% & $24,8 \pm 0,68$ & $22,5 \pm 0,71$ & $22,1 \pm 0,57$ & $22,9 \pm 0,62$ \\
\hline Calcium, mmol / 1 & $3,70 \pm 0,66$ & $4,80 \pm 0,43$ & $4,91 \pm 0,67$ & $4,51 \pm 0,63$ \\
\hline Phosphorus, mmol / & $2,43 \pm 0,22$ & $2,28 \pm 0,39$ & $2,20 \pm 0,45$ & $2,26 \pm 0,31$ \\
\hline Cholesterol, mmol / & $1,47 \pm 0,31$ & $1,46 \pm 0,38$ & $1,44 \pm 0,35$ & $1,49 \pm 0,38$ \\
\hline Glucose, mmol / & $16,2 \pm 0,65$ & $16,7 \pm 0,61$ & $16,3 \pm 0,82$ & $16,4 \pm 0,77$ \\
\hline AST u / L & $233,8 \pm 7,46$ & $200,2 \pm 6,89 * *$ & $199,7 \pm 8,14 * *$ & $198,6 \pm 7,85^{* *}$ \\
\hline ALT u / L & $62,9 \pm 3,66$ & $57,6 \pm 3,29$ & $58,2 \pm 3,54$ & $58,8 \pm 3,77$ \\
\hline
\end{tabular}

Note: - * $p<0,05$; 
From the data presented in the table, at the end of the experimental period, the total protein content in the blood serum of the chickens of the experimental groups was $4.8-5.5 \%$ higher than the control values, but these changes did not have statistically significant differences.

The relative content of albumin in the blood serum significantly increased in chickens 2,3 , and 4 of the experimental groups by $6.2,7.1$, and $6.9 \%$, respectively, after the use of drugs ( $p<0.01$ ), which can be explained by the activation of proteosynthesis in the liver.

The proportion of $\alpha$-globulins in the protein of chickens from the experimental groups did not statistically differ from the control, although it tended to decrease. As for $\beta$-globulins, in 2, 3, and 4 experimental groups their number increased by $10.3,9.6$, and $8.3 \%$, respectively, in all cases the difference with the control was confirmed statistically ( $\mathrm{p}<0.05$ ). As you know, the $\beta$-globulin fraction contains complement components and immunoglobulins. Therefore, it can be assumed that Vitaferm helps to stimulate the body's immune system.

It should be noted that the level of $\gamma$-globulins in chickens of all experimental groups tended to decrease, but these changes did not differ statistically from the control ones.

The level of calcium and phosphorus was determined from the mineral elements. In all the chickens in the experiment, the content of these two elements corresponded to the physiological norm. At the same time, in the experimental groups, the content of total calcium tended to increase, and inorganic phosphorus to decrease, however, these changes did not have a statistically significant difference with the control.

The determination of cholesterol in blood serum has the greatest clinical significance in assessing lipid metabolism. In our studies, the cholesterol level in chickens from the experimental groups did not have a statistically significant difference with the control, which indicates the absence of a negative effect of the studied drugs on lipid metabolism.

At the end of the experimental period in all experimental groups, there was a decrease in the activity of aspartate aminotransferase by $14.4,14.6$, and $15.1 \%$, respectively, compared with the control, in all cases $p$ $<0.01$.

Since the increased content of these enzymes in the blood serum is observed with the destruction of cardiomyocytes, liver diseases, necrosis of skeletal muscles, then after the application of the vitaminenzyme complex, the normalization of the work of these organs occurred, which, affected the increase in the increase in the live weight of chickens.

It should also be noted a decrease in the activity of alanine aminetransferase in all experimental groups, however, these changes were not statistically confirmed with the control ones.

\section{Conclusion}

The use of Vitafarm and Avizim 110 to broiler chickens has a positive effect on the biochemical composition of the poultry blood, contributes to an increase in safety and productivity. Moreover, the complete exclusion of antibacterial drugs from the diet of poultry does not harm the body.

\section{Practical application}

For the complete or partial exclusion of antibacterial drugs from the scheme of antiepizootic measures, the vitamin-enzyme complex Vitaferm is proposed. The drug is recommended to be applied to broiler chickens with feed at the rate of $10.0 \mathrm{~g} / \mathrm{kg}$ starting from day old for 10 days.

\section{References}

1. G.R. Gibson, M.B. Roberfroid, Dietary modulation of the human colonic microbiota: Introducing the concept of prebiotics, J. Nutr., 125, 1401-1412 (1995)

2. V.O. Ezhkov, Features of metabolic disorders in chickens in the conditions of industrial poultry farming, in: Mater. International. NDT on animal pathophysiology, pp. 57-58 (Saint Petersburg, 2006)

3. M.M. Goryacheva, Alternative to antibiotics, Poultry products, 1, 16-19 (2013)

4. N.Y. Plesovskikh, The use of enzyme preparations in wheat and barley feed mixtures for growing chickens - broilers (Omsk, 1999) 16 p.

5. T.M. Okolelova, A.V. Kulakov, S.A. Moloskin, Vitamin and mineral nutrition of agricultural poultry (Moscow, 2000) $78 \mathrm{p}$.

6. O. Simon, F. Igbasan, In vitro properties of phytases from various microbial origins, International Journal of Food Science and Technology, 37, 813-822 (2002)

7. A. Barletta, Current Market and Expected Developments, in: Enzymes in farm animal nutrition, 2nd edition, pp. 1-12 (2010)

8. S.I. Kononenko, N.S. Paksyutov, Enzyme preparation Ronozyme WX in compound feeds with triticale for young pigs, Proceedings of the Kuban State Agrarian University, 4(19), 169-170 (2009)

9. M.F. Isaksen, A.J. Cowieson, K.M. Kragh, Starchand protein-degrading enzymes: biochemistry, enzymology and characteristics relevant to animal feed use, in: Enzymes in farm animal nutrition, 2nd edition, pp. 85-96 (2010)

10. L.V. Reznichenko, S.B. Noskov, A.A. Reznichenko, M.N. Penzeva, A.A. Manohin, The efficiency of new vitamin-enzyme complex in the diets of pigs, International Journal of Pharmacy and Technology, 8(4), 26882-26888 (2016)

11. W. Vahjen, O. Simon, Biochemical characteristics of non-starch polysaccharide hydrolyzing enzyme preparations designed as feed additives for poultry and piglet nutrition, Archives of Animal Nutrition, 52, 1-14 (1999) 
12. T.M. Okolelova, N.V. Kulakova et al., Feeds and enzymes (Sergiev Posad, 2001) 112 p.

13. L.N. Skvortsova, The use of prebiotics in growing broiler chickens, Reports of the RAHSN, 3, 38-40 (2010)

14. L.V. Reznichenko, O. Bykova, F. Denisova, A. Manokhin, S. Vodyanitskaia, R. Shcherbinin, New Biologically Active Additives in Broilers Diets,
International Journal of Advanced Bio-technology and Research (IJABR), 10(2), 560-566 (2019)

15. I.I. Kochish, E.P. Lachugin, O.I. Kochish, S.V. Makarov, The use of an immunocorrecting feed additive in the diets of meat chickens at ZAO Belgorodsky Broiler, Russian veterinary journal. Farm animals, 2, 13-15 (2012) 